\title{
Medical ozone therapy in facet joint syndrome: an overview of sonoanatomy, ultrasound-guided injection techniques and potential mechanism of action
}

\author{
Eleonora Latini ${ }^{\star}$, Enrico Roberto Curci, Sveva Maria Nusca, Alessandra Lacopo, Francesca Musa, Flavia Santoboni, \\ Donatella Trischitta, Mario Vetrano, Maria Chiara Vulpiani \\ Unit of Physical Medicine and Rehabilitation, Sant'Andrea Hospital, “Sapienza” University of Rome, Rome, Italy \\ *Correspondence to: Eleonora Latini, MD, eleonora_gib@yahoo.it. \\ orcid: 0000-0003-0032-215X (Eleonora Latini)
}

\section{Abstract}

Facet joint osteoarthritis is the most prevalent source of facet joint pain and represents a significant cause of low back pain. Oxygen-ozone therapy has been shown to have positive results in acute and chronic spinal degeneration diseases and it could be a safe and efficacious alternative to traditional facet joint conservative treatments. This review article explains the interventional facet joint management with ultrasound-guided oxygen-ozone therapy, providing an anatomy/sonoanatomy overview of lumbar facet joints and summarizing the potential mechanism of action of oxygen-ozone in the treatment of facet joint osteoarthritis, not yet fully understood.

Key words: facet joint injection; facet joint; facet joint management; facet joint syndrome; facet joint ultrasound-guided injections; low back pain; oxygen-ozone; ozone; ozone therapy; ultrasound-guided oxygen-ozone therapy

doi: $10.4103 / 2045-9912.318859$

How to cite this article: Latini E, Curci ER, Nusca SM, Lacopo A, Musa F, Santoboni F, Trischitta D, Vetrano M, Vulpiani MC . Medical ozone therapy in facet joint syndrome: an overview of sonoanatomy, ultrasound-guided injection techniques and potential mechanism of action. Med Gas Res. 2021;11(4):145-151.

\section{INTRODUCTION}

Low back pain (LBP) is one of the most prevalent musculoskeletal disorders encountered in worldwide clinical practice. It is characterized by pain, muscle tension, or stiffness localized below the costal margin and above the inferior gluteal folds, with or without referred leg pain (lumbosacral radiculopathy). Lifetime prevalence is approximately estimated to be $70-80 \%$ in industrialized countries, ${ }^{1}$ and a recent study has shown that up to $5.0-10.0 \%$ of the cases will suffer from chronic LBP. ${ }^{2}$ Various spinal structures may be responsible of chronic LBP, including lumbar intervertebral discs, sacroiliac joints, lumbar facet joints, muscles, nerve roots and peripheral nerve tissue. The facet joint-related pain has been recognized as a potential cause of chronic spinal pain from $15 \%$ in younger patients to $40 \%$ in older patients. ${ }^{3,4}$ The most frequent form of facet pathology is facet joint osteoarthritis, and its estimated prevalence increases with age. ${ }^{5}$ Medical history, referred pain patterns, physical examination, and diagnostic imaging studies (standard radiographs, magnetic resonance imaging and computed tomography) may suggest but not confirm facet joint syndrome as a source of chronic LBP. In clinical practice, diagnostic blocks are the most accepted and reliable tool for diagnosing pain arising from the lumbar facet joints. ${ }^{6}$ Diagnostic blocks commonly include low-volume intraarticular injections of local anesthetic (lidocaine and/or bupivacaine), with or without steroids. ${ }^{7}$ A diagnostic positive facet joint block allows to identify patients may benefit from specific minimally invasive modalities of intervention ${ }^{7}$ such as intra-articular steroid injections and medial branch neurolysis, by radiofrequency denervation or cryoablation. ${ }^{8,9}$ These interventions are used after failure of conservative multimodal management, including drug therapy (acetaminophen, nonsteroidal anti-inflammatory drugs, skeletal muscle relaxants, antidepressants), physiotherapy and acupuncture. ${ }^{7}$ Oxygen-ozone $\left(\mathrm{O}_{2}-\mathrm{O}_{3}\right)$ has been shown to have positive results in acute and chronic spinal-degeneration diseases and it could be a safe and efficacious alternative to failed traditional facet joint conservative treatments. ${ }^{10,11}$ The primary purpose of this review article is to describe a specific interventional facet joint management with ultrasound-guided $\mathrm{O}_{2}-\mathrm{O}_{3}$ therapy, providing an anatomy and sonoanatomy overview of lumbar facet joints. At last, although the mechanism of action of $\mathrm{O}_{2}-\mathrm{O}_{3}$ therapy is not fully understood, this review underlines its potential biological effects in the treatment of facet joint osteoarthritis.

The authors have conducted between April and June 2020 a comprehensive literature search in PubMed/Medline (NLM), Cochrane Library, Scopus and PEDro databases. The search was performed using the following key words: "facet joint," "facet joint syndrome," "zygapophyseal joint," "facet joint injection," "facet joint management," "imaging-guided injections," "interventional spinal procedures," "low back pain," "ozone," "oxygen-ozone," "oxygen-ozone therapy," "ultrasound-guided oxygen-ozone therapy." Among the reference list of most relevant studies, additional studies were identified in order to achieve the greatest number of available studies on the scientific literature. 


\section{Lumbar Facet Joint Anatomy}

Facet joints, otherwise known as zygapophyseal or apophyseal joints, are the only true synovial joints in the spine. They are formed by a hyaline cartilage covering subchondral bone, a synovial membrane, a tough fibrous capsule with a capsular ligament and a meniscoid structure. ${ }^{12}$ The volume of the joint capsule is small, typically of $1-2 \mathrm{~mL} .^{13}$

Each vertebra has two facet joints. They form the posterolateral articulation connecting the superior articular process of a vertebra with the inferior articular process of the vertebra above. The morphometry of the facet joints surfaces differs between the region of the spine and it is linked to their biomechanical function. The superior facet of the inferior vertebra is roughly planar in the cervical and thoracic regions; instead it is less planar and more convex in the lumbar region. The opposing inferior facet of the superior vertebra is concave at each level. ${ }^{14,15}$

At every vertebral level, except for C1-2, zygapophyseal joints and intervertebral disk form an entity defined the threejoint complex which stabilizes the spine, allowing for flexion and extension of the spine, limiting rotation and preventing the vertebrae from slipping over each other. ${ }^{14,16}$

The pattern orientation of the articular surface changes throughout the spine as well, and it guides and limits the excursion of the motion segments. In the cervical region, the inclined angle of the articular surface is approximately $45^{\circ}$ in the sagittal plane and $70^{\circ}-96^{\circ}$ in the axial plane. In the thoracic spine, the joint orientation is approximately at an angle of $60^{\circ}$ to the horizontal plane and roughly at an angle of $20^{\circ}$ to the axial plane. In the lumbar region, the facet joints gradually become more vertically-oriented, the inclination angle is $82^{\circ}-86^{\circ}$ in the sagittal plane and an average of only $8^{\circ}$ rotation is allowed. This orientation in the lower thoracic and lumbar regions limits the flexibility in both lateral bending and rotation, protecting the spinal cord and neural structures from injury. ${ }^{14,15}$

Two adjacent vertebrae, the intervertebral disc, spinal ligaments (flavum, supraspinous, interspinous, anterior and posterior longitudinal) and facet joints between them constitute functional spinal unit or spinal motion segment, the smallest motion segment of the spine that reflects the biomechanical properties of the entire vertebral column. ${ }^{17}$

The vertebral body and the intervertebral discs are main load bearing structures in each motion segment, transmitting approximately $70 \%$ of applied axial compression, and instead the remaining $30 \%$ of the load is distributed through the facet joint, especially when the spine is extended. ${ }^{14,17}$

Each facet joint receives dual innervation from the medial branch of the dorsal ramus of the nerve arising at the same level and also the medial branch of the nerve one level above. ${ }^{18}$ In the facet joints there are also mechanoreceptors lining the facet capsule, so they may also have proprioceptive functions. Nociceptive and autonomic nerve fibers have been identified in the capsule of the facet joints, subchondral bone and synovium. ${ }^{19}$

\section{Lumbar Facet Joint Sonoanatomy}

During scanning of the lumbar spine, the patient is placed in a prone position with a pillow under the abdomen to compensate for the lumbar lordosis. A convex probe with a low-frequency (3-8 MHz) is required to provide better penetration of soft tissue and wide field of view in order to visualize spine anatomical structures located deeper. Ultrasound parameters, such as reducing the beam frequency, adjusting the depth, focus, and gain settings, should be optimized to produce an optimal image and improve recognition of anatomy.

An accurate ultrasound evaluation of the lumbar facet joints can be performed in combination with the anatomical information obtained by sagittal and transverse scans. The ultrasound probe is placed over the lower lumbar spine approximately 3-4 $\mathrm{cm}$ lateral to the midline, in a parasagittal orientation (paramedian sagittal transverse process view). The transverse processes appear as hyperechoic curvilinear structures with finger-like acoustic shadowing beneath, separated by the striated psoas major muscle. This sonographic pattern has known as the "trident sign" (Figure 1A).

Maintaining a sagittal orientation, the transducer is moved medially until to observe the facet joint column, which appears as a continuous hyperechoic wavy line with acoustic shadowing beneath (paramedian sagittal articular process view). In this view, the typical sonographic appearance resembles a series of camel humps ("camel-hump sign"), where each hump represents the facet joint formed by superior and inferior articular processes of the consecutive vertebrae (Figure 1B). An accurate identification of different spinal levels can be determined by counting the facet joints from the lumbosacral facet joint toward cranial direction up to the first lumbar spine vertebrae (counting-up approach) or by a "counting-down approach" from the lower thoracic vertebrae or the upper lumbar spine, using the $12^{\text {th }}$ rib as a landmark. ${ }^{20}$

The probe can be tilted softly toward the midline, performing a paramedian oblique sagittal scan, to improve the accuracy of ultrasound to identify spinal segments. A succession of "sawtooth" hyperechogenic lines visualized in this view, corresponding to vertebral laminae, allows identifying the intervertebral spaces from L5/S1 to L1/L2 (Figure 1C). The facet joints lie in approximately the same transverse plane as the interlaminar space. Marking on the skin the intervertebral reference levels, an ultrasound view of the lumbar facet joint can be obtained turning the probe by $90^{\circ}$ into a transverse orientation (transverse interlaminar view).

In this view, the interspinous ligament appears as a hypoechoic midline vertical stripe, and deeply, two parallel hyperechoic lines of the posterior and anterior complex separated by the hypoechoic intrathecal space are visible. The articular processes of the facet joints and the transverse processes can be laterally recognized (Figure 1D). Normally, the articular processes should be symmetrically located on either side. An asymmetry should make us suspect the presence of a rotational deformity of the vertebral column, such as scoliosis.

\section{Oxygen-Ozone Ultrasound Guided Facet Joint INJECTION}

Ultrasound-guided facet injections are performed by a specialist experienced in the musculoskeletal ultrasound using a low-frequency curvilinear probe $(3-8 \mathrm{MHz})$.

The procedure is performed under strict sterile conditions: 
patient's skin is cleansed with antiseptics solutions, ultrasound probe is covered with a sterile sheath, and sterile ultrasound gel and sterile gloves are used. As described above, the patient is placed in prone position with the abdomen supported by the pillows to reduce the lumbar lordosis.

\section{Lateral to medial approach}

Once the appropriate lumbar spine level is visualized in the parasagittal views during the exploration technique previously described, the probe is rotated to obtain a transverse sonogram of the facet joint. Adjustments of the transducer alignment could be performed to identify the entrance to the facet joint between the inferior and superior articular processes. The target point is the middle portion of the joint, visible as hypoechoic space in the transverse sonogram. Under real-time sonographic guidance, a spinal needle (22 Gauge, $90 \mathrm{~mm}$ ) is inserted $3-4 \mathrm{~cm}$ laterally from the midline on the lateral end of the transducer in-plane technique. The insertion angle is approximately $45^{\circ}$ to the axial plane, and the needle advances in a lateral to medial trajectory. The needle is directed down to the junction between the medial aspect of the inferior articular process and the lateral aspect of the superior articular process. The in-plane approach allows visualizing throughout the entire procedure the complete needle path, which appears as a bright line in the transverse view. This technique provides real-time monitoring and allows accurate repositioning of the needle.

After the needle tip reaches the bone surface of the facet joint (intraarticular bone contact) (Figure 1E), 2-3 $\mathrm{mL}$ of $\mathrm{O}_{2}-\mathrm{O}_{3}$ mixture are injected in intra-articular space until resistance is encountered, subsequently $8 \mathrm{~mL}$ of $\mathrm{O}_{2}-\mathrm{O}_{3}$ mixture are administered in periarticular region around the posterior facet joint capsule, at $15-20 \mu \mathrm{g} / \mathrm{mL}$ concentration. $\mathrm{O}_{2}-\mathrm{O}_{3}$ mixture appears as hyperechoic area in the peri-facet joint soft tissue with a well-defined shadow beneath (Figure 1F and G). The same procedure can be repeated in other lumbar segments.

The intra-articular injection of the facet joint is not always possible: the joint opening might be obscured by the bony spurs (facet joint hypertrophy) and the great tension between its ligaments and its capsule could make difficult to access into the narrow joint. In this case, periarticular injection is an acceptable alternative and only the periarticular area will be reached, ${ }^{21}$ exploiting the muscle relaxant action of ozone.

The lateral to medial approach was for the first time proposed by Galiano et al. ${ }^{22,23}$ and the feasibility and accuracy of this ultrasound-guided facet joint approach have been validated by computed tomography images in an experimental setting ${ }^{22}$ and in a prospective randomized clinical trial. ${ }^{23}$

\section{Caudal to cranial approach}

Another ultrasound-guided approach for facet joint injection with $\mathrm{O}_{2}-\mathrm{O}_{3}$ therapy can be performed in the paramedian sagittal process articular views. The articular processes are visible as a continuous hyperechoic line of "humps" with acoustic shadowing beneath, and the bony contour of the superior articular process is usually more superficial than the inferior articular process. The target point is the space between the articular lines of the superior articular process and inferior articular process (Figure 1H). Under real-time sonographic guidance, a spinal needle ( 22 Gauge, $90 \mathrm{~mm}$ ) is introduced on the inferior end of the probe in-plane technique. The insertion angle is slightly lower $45^{\circ}$ respect to the longitudinal plane, and the needle advances in a caudal to cranial direction. After the needle tip reaches the target area, the probe can be turned $90^{\circ}$ to further confirm its position inside the facet joint space. If the needle position is correct, back in the longitudinal view, $\mathrm{O}_{2}-\mathrm{O}_{3}$ mixture is injected and the spread of the gaseous mixture is observed under ultrasound monitoring. The mixture should be administered very slowly with gentle pressure, avoiding the rupture of the joint capsule and pain.

The caudal to cranial approach allows performing the facet joint injection at various levels at the same time, with a single-needle insertion. Moreover, L5-S1 facet joint injection, harder to perform in lateral to medial technique owing to the proximity of the iliac crest, can be easily performed without obstacle the needle advancement.

\section{OXygen-0Zone Therapy in Facet Joint OSteOARTHRITIS: Potential MeChanISMS OF ACTION}

Facet joint degenerative osteoarthritis is the most common source of facet joint pain. The facet joints develop degenerative changes, reflecting the progressive stresses placed upon the joint after overuse and injury. ${ }^{24}$ The earliest osteoarthritic changes involve the articular cartilage, joint space and capsule. The cartilage damage begins with fibrillation and shallow pitting in focal locations of the joint, especially at the superior and inferior poles where the articular processes are in contact during flexion and extension; followed by deeper fibrillation, fissuring and flaking. ${ }^{25}$ The joint space is narrowed, while joint capsule show fibrosis and increased vascularization, with multiple inflammatory mediators. ${ }^{26}$ In later stages, there is joint hypertrophy, osteophytosis and progressive subchondral bone thickening until to sclerosis and erosions. Similar to synovial peripheral joint osteoarthritis, facet joint osteoarthritis is a continuum between joint space narrowing, loss of synovial fluid, loss of cartilage and bony overgrowth. ${ }^{24,27-29}$ Several studies have shown an increase of immune cell infiltration and pro-inflammatory cytokines (tumor necrosis factor- $\alpha$ (TNF- $\alpha$ ), interleukin (IL)-1 $\beta$, IL-6, and prostaglandins), ${ }^{30,31}$ as well as cartilage-degrading enzymes, ${ }^{26}$ suggesting an important role of these molecules in structural and molecular changes observed in degenerative face joint tissues. Nevertheless, also antiinflammatory cytokines and inhibitors of cartilage-degrading enzymes are upregulated in parallel (IL-10, IL-13, tissue inhibitor of metalloproteinase-2 and tissue inhibitor of metalloproteinase-3), in a vain attempt of reparative response. ${ }^{32-34}$

In addition to multiple inflammatory mediators, the tissues harvested from degenerative lumbar facet joint show higher levels of angiogenic factors. ${ }^{26}$ Previous studies ${ }^{35,36}$ have underlined that the angiogenesis is involved in the joint degenerative disease and pain through the development of inflammation and neurogenesis. Through the release of vasoactive substances, the angiogenesis facilitates the influx of inflammatory cells into the joint, and promotes the growth of new afferent pain fibers and the upregulation of pain mediators (substance P, 

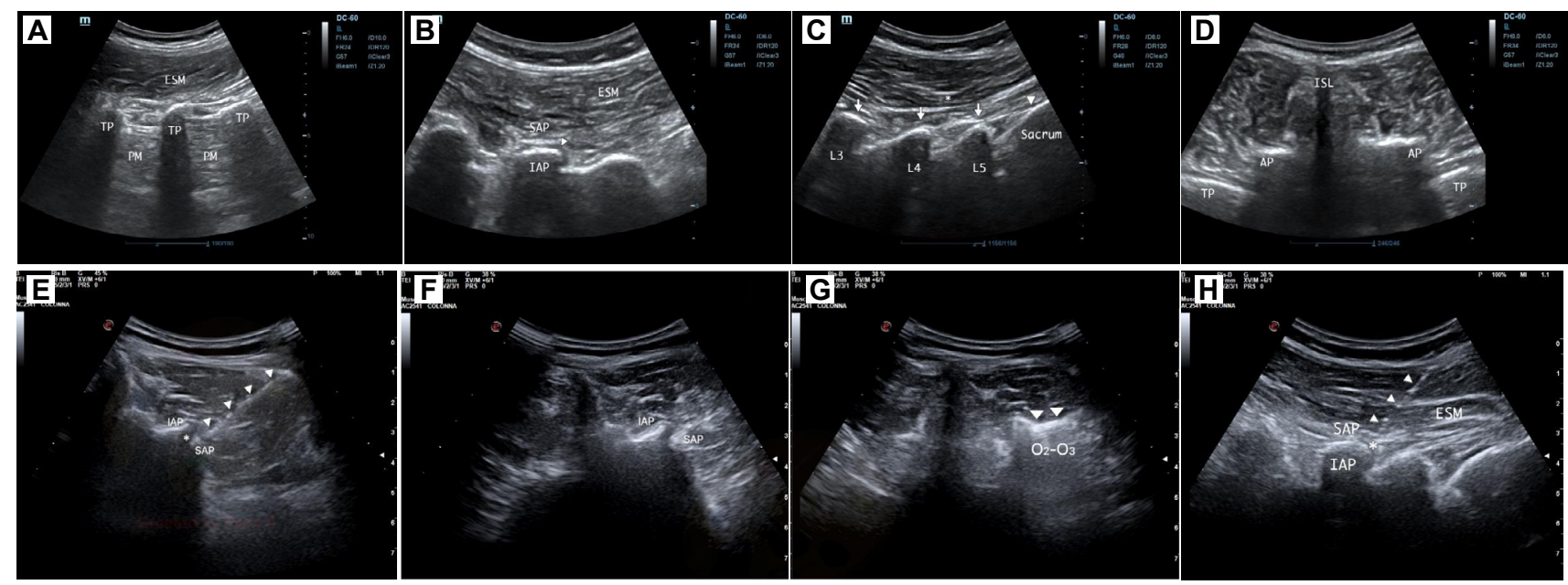

Figure 1: Imaging results of effect of facet joint injection with oxygen-ozone $\left(\mathrm{O}_{2}-\mathrm{O}_{3}\right)$.

Note: (A) Paramedian sagittal transverse processes view. The hyperechoic reflections of the transverse processes (TP) with their acoustic shadow produce the "trident sign." The psoas muscle (PM) with its typical hypoechoic and striated appearance, is visible between the transverse processes. The erector spinae muscle (ESM) lies superficially to the transverse processes. (B) Paramedian sagittal articular process view. The articular processes are visible as a continuous hyperechoic line of "humps" with acoustic shadowing beneath, and the bony contour of the superior articular process (SAP) is usually more superficial than the inferior articular process (IAP). The facet joint space (arrowhead) is situated between the articular lines of the SAP and IAP. The ESM lies superficially to the articular processes. (C) Paramedian sagittal oblique view. The sacrum (arrowhead) is recognizable as a horizontal hyperechoic curvilinear structure, the L3-5 laminae (arrows) have the typical "sawtooth" appearance, and the erector spinae muscles (asterisk) are hypoechoic and lie superficial to the laminae. (D) Transverse interlaminar view. Interspinous ligament (ISL) is visible in the midline. The articular process (AP) and the TP are visible laterally on either side of the midline. (E) Ultrasound-guided facet joint injections in lateral to medial approach. The asterisk indicates the entry zone (hypoechoic space) into the lumbar facet joint between the medial aspect of the IAP and the lateral aspect of the SAP. The arrowheads indicate the needle trajectory. $(F, G)$ Facet joint injection with $\mathrm{O}_{2}-\mathrm{O}_{3}$ in transverse sonogram. $(\mathrm{F})$ The medial aspect of the IAP and the lateral aspect of the SAP is easily recognizable. (G) The $\mathrm{O}_{2}-\mathrm{O}_{3}$ mixture (arrowheads) appears as hyperechoic area in the peri-facet joint soft tissue with a well-defined shadow beneath. The $\mathrm{O}_{2}-\mathrm{O}_{3}$ mixture was produced by means of a Multiossigen Medical 99IR generator (Multiossigen S.p.A., Gorle, Italy). (H) Ultrasound-guided facet joint injections in caudal to cranial approach. The articular processes are visible as a continuous hyperechoic line of "humps" with acoustic shadowing beneath. The needle (arrowheads) is directed to the space (asterisk) between the articular lines of the SAP and IAP. A-D were obtained by means of a Mindray DC-60 Ultrasound (Mindray Medical S.R.L, Milano, Italy). E-H were obtained by means of a ESAOTE MyLab OMEGA Ultrasound (Esaote S.p.A, Genova, Italy).

inducible nitric oxide synthase, cyclooxygenase-2)..$^{37,38}$

The development and progression of osteoarthrosis, as with other degenerative diseases, are significantly associated with the oxidative stress and the overproduction of reactive oxygen species (ROS). ${ }^{39,40}$ ROS are short-lived, unstable and highly reactive radicals containing oxygen molecules, such as hydroxyl radical $\left(\mathrm{OH}^{-}\right)$, superoxide anion $\left(\mathrm{O}_{2}^{-}\right)$, hydrogen peroxide and nitric oxide, recognized as a major factor in progressive cartilage degradation.

In normal cartilage, chondrocytes produce low levels of ROS and show a subtle equilibrium between free radical production and their scavenging mechanism, such as superoxide dismutase, catalase, glutathione peroxidase, glutathione, nicotinamide adenine dinucleotide phosphate ubiquinone oxidoreductase, ascorbic acid (vitamin C) and $\alpha$-tocopherol (vitamin E). ROS regulate intracellular signaling processes contributing to the maintenance of cartilage homeostasis, and modulate chondrocyte senescence and apoptosis, extracellular matrix synthesis and degradation, gene expression and cytokine production. ${ }^{41,42}$

In osteoarthritic cartilage, excessive generation of ROS and oxidative stress have been found. ${ }^{43-45}$ Abnormal levels of ROS, mainly catalyzed by nicotinamide adenine dinucleotide phosphate oxidase, are produced in articular chondrocytes in response to partial oxygen pressure fluctuations, high degree of mechanical stress and immunomodulatory mediators (IL-1 $\beta$, TNF- $\alpha$, interferon- $\gamma$, IL-17). ${ }^{42}$ Simultaneously, important antioxidant enzymes (superoxide dismutase, catalase, glutathione peroxidase) are decreased, confirming the role of oxidative stress in the development and progression of osteoarthritis. ${ }^{46-48}$ In human articular cartilage, the over-produced ROS cause oxidative damage of cellular lipids, proteins and DNA, impairing cell biological functionality and leading to cytotoxicity. ${ }^{42}$ Oxidative stress-induced dysfunctions induce apoptosis and premature senescence of synoviocyte and cartilage chondrocytes, activating apoptotic pathways mediated by caspase- 3 and caspase-9, suppressing pro-survival Akt kinase activity and through mitochondrial injury. ${ }^{49,50}$ ROS may also contribute to the loss of chondrocyte responsiveness to growth factors. Moreover, the increased oxidative stress activates the nuclear factor- $\kappa \mathrm{B}(\mathrm{NF}-\mathrm{\kappa} \mathrm{B})$, a redox-sensitive transcription factor, contributing to the proinflammatory phenotypic alterations in osteoarthritic tissue.

$\mathrm{O}_{2}-\mathrm{O}_{3}$ therapy has been widely used in the field of musculoskeletal disorders and has shown therapeutic and biological effects owing to its antalgic, anti-inflammatory, antioxidant and immunomodulatory properties. ${ }^{11} \mathrm{O}_{2}-\mathrm{O}_{3}$ has shown positive results in spinal-degeneration diseases due to lumbar-disk herniation or facet joint syndrome. ${ }^{10,11,51,52}$ The clinical efficacy of $\mathrm{O}_{2}-\mathrm{O}_{3}$ are mediated by: i) activating the cellular metabolism, ii) reducing proinflammatory cytokines and prostaglandins synthesis, iii) increasing immunosuppressor cytokines, iv) reducing oxidative stress as an adaptive response of chronic oxidative stress, and iv) ameliorating the tissue $\mathrm{O}_{2}$ supply. ${ }^{53-56}$

In osteoarthritis, $\mathrm{O}_{2}-\mathrm{O}_{3}$ therapy acts as a bioregulator of the inflammatory response, coordinating the expression of a 
wide range of genes and cytokines. It increases transforming growth factor- $\beta$, which is an essential factor in tissue remodeling, while reduces proinflammatory cytokine concentrations (TNF- $\alpha$ and IL-8) involved in the development and progression of osteoarthritis. ${ }^{57}$

$\mathrm{O}_{2}-\mathrm{O}_{3}$ appears to inhibit the NF- $\mathrm{KB}$ pathway, known as one of the main signaling pathways interconnected with osteoarthritis. NF- $\mathrm{KB}$ signaling induces the expression of enzyme inducible nitric oxide synthase, prostaglandin E2, cyclooxygenase- 2 and through a positive feedback loop the release of proinflammatory cytokines (IL- $1 \beta$, IL-6, TNF- $\alpha$ ). ${ }^{58}$ These cytokines are implicated in the inhibition of extracellular matrix components synthesis and in matrix metalloproteinase activation (matrix metalloproteinase-1, matrix metalloproteinase-8, matrix metalloproteinase-9, matrix metalloproteinase-13), causing cartilage damage, disturbance of the metabolic balance of the cartilage matrix, until apoptosis. ${ }^{59,60} \mathrm{NF}-\kappa \mathrm{B}$ pathway can be activated directly by ROS or through other pro-inflammatory mediators such as TNF- $\alpha$, a cytokine strongly associated with joint and bone injury. ${ }^{61}$ The ROS-mediated NF- $\kappa \mathrm{B}$ activation is enhanced by the activity of tyrosine kinases through the phosphorylation of I $\mathrm{B}$, a subunit of the transcription factor $\mathrm{NF}-\kappa \mathrm{B} .{ }^{53} \mathrm{O}_{2}-\mathrm{O}_{3}$ can cause $\mathrm{NF}-\kappa \mathrm{B}$ inhibition directly by means of the decrease of ROS production or indirectly through the inhibition of TNF- $\alpha$. In this context, $\mathrm{O}_{2}-\mathrm{O}_{3}$ therapy may interrupt the harmful NF$\kappa \mathrm{B}$ pathway causing a reduction of the inflammation and an inhibition of apoptotic cell death (Figure 2).

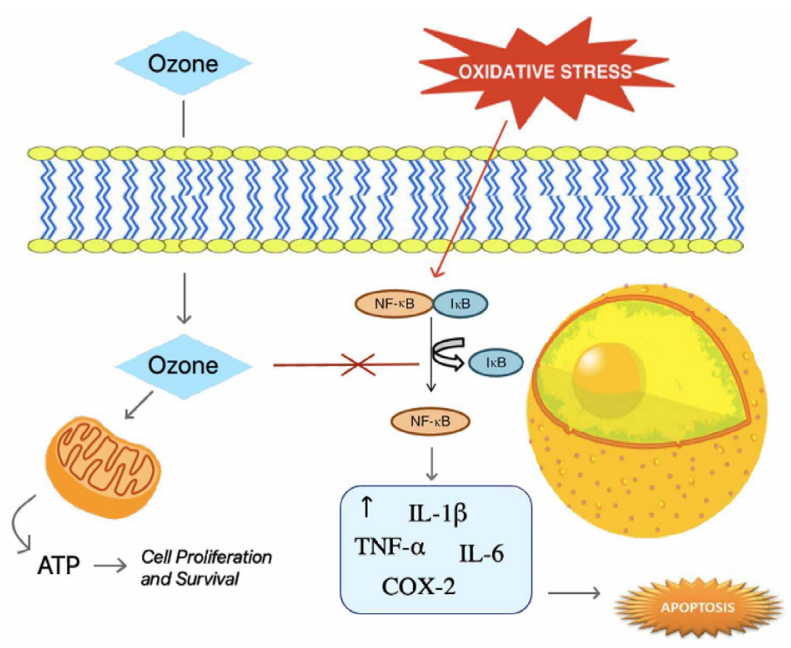

Figure 2: Potential mechanism of action of oxygen-ozone therapy Note: Oxidative stress is involved in NF-kB pathways activation. NF-kB signaling induces the release of proinflammatory cytokines (IL-1 $1 \beta, I L-6, T N F-\alpha, C O X-2)$, implicated in the inhibition of extracellular matrix components synthesis and in matrix metalloproteinase activation causing cartilage damage, disturbance of the metabolic balance of the cartilage matrix, until apoptosis. Oxygen-ozone mixture attenuates inflammatory responses by inhibiting the activation of NF-kB pathway, resulting in cell proliferation and survival. ATP: Adenosine triphosphate; COX-2: cyclooxygenase-2; IKB: inhibitor of nuclear factor-kB; IL: interleukin; NF-kB: nuclear factor-kB; TNF-a: tumor necrosis factor- $\alpha$.

Moreover, the therapeutic efficacy of $\mathrm{O}_{2}-\mathrm{O}_{3}$ therapy is due to the repeated and controlled oxidative stress produced by the reaction of $\mathrm{O}_{3}$ with several biological components. Transi- tory and moderate administration of $\mathrm{O}_{2}-\mathrm{O}_{3}$ mixture generates second messengers in various intracellular signaling pathways with activation of nuclear transcriptional factors and induction of antioxidant enzymes (superoxide dismutase, catalase and glutathione peroxidase). These upregulate the antioxidant defenses and promote an adaptation to chronic oxidative stress through the normalization of the cellular redox balance. ${ }^{55,56}$ In this context, $\mathrm{O}_{2}-\mathrm{O}_{3}$ therapy can prevent the progressive cartilage damage mediated by overproduction of superoxides, involved in degenerative osteoarthrosis. $\mathrm{O}_{2}-\mathrm{O}_{3}$ also protects against cartilage damage due to overproduction of nitric oxide, reducing the expression of the enzyme inducible nitric oxide synthase at the transcriptional level due to NF- $\mathrm{BB}$ inhibition. ${ }^{62}$ In addiction, $\mathrm{O}_{2}-\mathrm{O}_{3}$ therapy promotes effective oxygen utilization in the mitochondrial respiratory chain, stimulating the production of adenosine triphosphate through the glycolysis enzymatic pathway in damaged cartilage cells, and preventing cell death.

\section{CONCLUSION}

$\mathrm{O}_{2}-\mathrm{O}_{3}$ therapy is becoming an effective treatment option for musculoskeletal disorders and it could be an efficacious and valid alternative to traditional facet joint interventional treatments. Unlike traditional fluoroscopic or computedtomography guided procedures that are associated with radiation exposure, scarce availability and high costs, the ultrasound-guided $\mathrm{O}_{2}-\mathrm{O}_{3}$ is not expensive and easily available, without radiation exposure. The $\mathrm{O}_{2}-\mathrm{O}_{3}$ mechanism of action has not been fully understood; however it would seem to attenuate inflammatory responses by inhibiting the activation

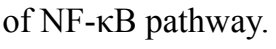

Author contributions
All the authors have made substantial contributions to the work report-
ed in the manuscript. All authors have participated in the conception,
design intellectual, and content of this work. Furthermore, EL, ERC,
AL, and FM have worked on the literature search and on the writing
of the manuscript and its editing. SMN, FS, DT, MCV, and MV have
contributed to the editing and review of the manuscript. EL also acted
as the guarantor for the manuscript. All authors approved the final
version of this manuscript.
Conflicts of interest
None.
Financial support
None.
Copyright license agreement
The Copyright License Agreement has been signed by all authors
before publication.
Plagiarism check
Checked twice by iThenticate.
Peer review
Externally peer reviewed.
Open access statement
This is an open access journal, and articles are distributed under
the terms of the Creative Commons Attribution-NonCommercial-
ShareAlike 4.0 License, which allows others to remix, tweak, and
build upon the work non-commercially, as long as appropriate credit
is given and the new creations are licensed under the identical terms.

\section{REFERENCES}

1. Maher C, Underwood M, Buchbinder R. Non-specific low back pain. Lancet. 2017;389:736-747. 
2. Liao ZT, Pan YF, Huang JL, et al. An epidemiological survey of low back pain and axial spondyloarthritis in a Chinese Han population. Scand J Rheumatol. 2009;38:455-459.

3. Perolat R, Kastler A, Nicot B, et al. Facet joint syndrome: from diagnosis to interventional management. Insights Imaging. 2018;9:773-789.

4. Hsieh CC, Wang JD, Lin RM, Lin CJ, Huang KY. Adjacent disc and facet joint degeneration in young adults with low-grade spondylolytic spondylolisthesis: A magnetic resonance imaging study. J Formos Med Assoc. 2015;114:1211-1215.

5. Almeer G, Azzopardi C, Kho J, Gupta H, James SL, Botchu R. Anatomy and pathology of facet joint. J Orthop. 2020;22:109-117.

6. Manchikanti L, Hirsch JA, Falco FJ, Boswell MV. Management of lumbar zygapophysial (facet) joint pain. World J Orthop. 2016;7:315-337.

7. Won HS, Yang M, Kim YD. Facet joint injections for management of low back pain: a clinically focused review. Anesth Pain Med (Seoul). 2020;15:8-18.

8. Manchikanti L, Kaye AD, Boswell MV, et al. A systematic review and best evidence synthesis of the effectiveness of therapeutic facet joint interventions in managing chronic spinal pain. Pain Physician. 2015;18:E535-582.

9. Manchikanti L, Kaye AD, Soin A, et al. Comprehensive evidencebased guidelines for facet joint interventions in the management of chronic spinal pain: American Society of Interventional Pain Physicians (ASIPP) Guidelines Facet Joint Interventions 2020 Guidelines. Pain Physician. 2020;23:S1-127.

10. Bocci V, Borrelli E, Zanardi I, Travagli V. The usefulness of ozone treatment in spinal pain. Drug Des Devel Ther. 2015;9:2677-2685.

11. Seyam O, Smith NL, Reid I, Gandhi J, Jiang W, Khan SA. Clinical utility of ozone therapy for musculoskeletal disorders. Med Gas Res. 2018;8:103-110.

12. Kapetanakis S, Gkantsinikoudis N. Anatomy of lumbar facet joint: a comprehensive review. Folia Morphol (Warsz). 2020; doi: 10.5603/FM.a2020.0122.

13. O'Leary SA, Paschos NK, Link JM, Klineberg EO, Hu JC, Athanasiou KA. Facet joints of the spine: structure-function relationships, problems and treatments, and the potential for regeneration. Annu Rev Biomed Eng. 2018;20:145-170.

14. Inoue $\mathrm{N}$, Orías AAE, Segami K. Biomechanics of the lumbar facet joint. Spine Surg Relat Res. 2020;4:1-7.

15. Liu Z, Duan Y, Rong X, Wang B, Chen H, Liu H. Variation of facet joint orientation and tropism in lumbar degenerative spondylolisthesis and disc herniation at L4-L5: a systematic review and metaanalysis. Clin Neurol Neurosurg. 2017;161:41-47.

16. Shur N, Corrigan A, Agrawal K, Desai A, Gnanasegaran G. Radiological and radionuclide imaging of degenerative disease of the facet joints. Indian J Nucl Med. 2015;30:191-198.

17. Kushchayev SV, Glushko T, Jarraya M, et al. ABCs of the degenerative spine. Insights Imaging. 2018;9:253-274.

18. Kozera K, Ciszek B, Szaro P. Posterior branches of lumbar spinal nerves - part II: Lumbar facet syndrome - pathomechanism, symptomatology and diagnostic work-up. Ortop Traumatol Rehabil. 2017;19:101-109.

19. Bogduk N. Functional anatomy of the spine. Handb Clin Neurol. 2016;136:675-688

20. Jung H, Jeon S, Ahn S, Kim M, Choi Y. The validation of ultrasound-guided lumbar facet nerve blocks as confirmed by fluoroscopy. Asian Spine J. 2012;6:163-167.

21. Aguirre DA, Bermudez S, Diaz OM. Spinal CT-guided interventional procedures for management of chronic back pain. $J$ Vasc Interv Radiol. 2005;16:689-697.
22. Galiano K, Obwegeser AA, Bodner G, et al. Ultrasound guidance for facet joint injections in the lumbar spine: a computed tomography-controlled feasibility study. Anesth Analg. 2005;101:579-583, table of contents.

23. Galiano K, Obwegeser AA, Walch C, Schatzer R, Ploner F, Gruber H. Ultrasound-guided versus computed tomography-controlled facet joint injections in the lumbar spine: a prospective randomized clinical trial. Reg Anesth Pain Med. 2007;32:317-322.

24. Netzer C, Urech K, Hügle T, Benz RM, Geurts J, Schären S. Characterization of subchondral bone histopathology of facet joint osteoarthritis in lumbar spinal stenosis. J Orthop Res. 2016;34:14751480 .

25. Li J, Muehleman C, Abe Y, Masuda K. Prevalence of facet joint degeneration in association with intervertebral joint degeneration in a sample of organ donors. J Orthop Res. 2011;29:1267-1274.

26. Kim JS, Ali MH, Wydra F, et al. Characterization of degenerative human facet joints and facet joint capsular tissues. Osteoarthritis Cartilage. 2015;23:2242-2251.

27. Abramoff B, Caldera FE. Osteoarthritis: pathology, diagnosis, and treatment options. Med Clin North Am. 2020;104:293-311.

28. Clarençon F, Law-Ye B, Bienvenot P, Cormier É, Chiras J. The Degenerative Spine. Magn Reson Imaging Clin N Am. 2016;24:495513.

29. Cohen SP, Hurley RW, Christo PJ, Winkley J, Mohiuddin MM, Stojanovic MP. Clinical predictors of success and failure for lumbar facet radiofrequency denervation. Clin J Pain. 2007;23:45-52.

30. Igarashi A, Kikuchi S, Konno S, Olmarker K. Inflammatory cytokines released from the facet joint tissue in degenerative lumbar spinal disorders. Spine (Phila Pa 1976). 2004;29:2091-2095.

31. Willburger RE, Wittenberg RH. Prostaglandin release from lumbar disc and facet joint tissue. Spine (Phila Pa 1976). 1994;19:20682070.

32. Johnson CI, Argyle DJ, Clements DN. In vitro models for the study of osteoarthritis. Vet J. 2016;209:40-49.

33. He Y, Li Z, Alexander PG, et al. Pathogenesis of osteoarthritis: risk factors, regulatory pathways in chondrocytes, and experimental models. Biology (Basel). 2020;9:194.

34. Mobasheri A, Batt M. An update on the pathophysiology of osteoarthritis. Ann Phys Rehabil Med. 2016;59:333-339.

35. Yoo SA, Kwok SK, Kim WU. Proinflammatory role of vascular endothelial growth factor in the pathogenesis of rheumatoid arthritis: prospects for therapeutic intervention. Mediators Inflamm. 2008;2008:129873.

36. Ashraf S, Mapp PI, Walsh DA. Angiogenesis and the persistence of inflammation in a rat model of proliferative synovitis. Arthritis Rheum. 2010;62:1890-1898.

37. Ashraf S, Walsh DA. Angiogenesis in osteoarthritis. Curr Opin Rheumatol. 2008;20:573-580.

38. Mapp PI, Walsh DA. Mechanisms and targets of angiogenesis and nerve growth in osteoarthritis. Nat Rev Rheumatol. 2012;8:390398.

39. Zahan OM, Serban O, Gherman C, Fodor D. The evaluation of oxidative stress in osteoarthritis. Med Pharm Rep. 2020;93:12-22.

40. Lepetsos P, Papavassiliou AG. ROS/oxidative stress signaling in osteoarthritis. Biochim Biophys Acta. 2016;1862:576-591.

41. Bolduc JA, Collins JA, Loeser RF. Reactive oxygen species, aging and articular cartilage homeostasis. Free Radic Biol Med. 2019;132:73-82.

42. Henrotin YE, Bruckner P, Pujol JP. The role of reactive oxygen species in homeostasis and degradation of cartilage. Osteoarthritis Cartilage. 2003;11:747-755. 
43. Paździor M, Kiełczykowska M, Kurzepa J, Luchowska-Kocot $\mathrm{D}$, Kocot J, Musik I. The oxidative stress in knee osteoarthritis patients. an attempt of evaluation of possible compensatory effects occurring in the disease development. Medicina (Kaunas). 2019;55:150.

44. Drevet S, Gavazzi G, Grange L, Dupuy C, Lardy B. Reactive oxygen species and NADPH oxidase 4 involvement in osteoarthritis. Exp Gerontol. 2018;111:107-117.

45. Altindag O, Erel O, Aksoy N, Selek S, Celik H, Karaoglanoglu M. Increased oxidative stress and its relation with collagen metabolism in knee osteoarthritis. Rheumatol Int. 2007;27:339-344.

46. Ostalowska A, Birkner E, Wiecha M, et al. Lipid peroxidation and antioxidant enzymes in synovial fluid of patients with primary and secondary osteoarthritis of the knee joint. Osteoarthritis Cartilage. 2006; 14:139-145.

47. Regan EA, Bowler RP, Crapo JD. Joint fluid antioxidants are decreased in osteoarthritic joints compared to joints with macroscopically intact cartilage and subacute injury. Osteoarthritis Cartilage. 2008;16:515-521.

48. Fernandez-Moreno M, Soto-Hermida A, Pertega S, et al. Mitochondrial DNA (mtDNA) haplogroups and serum levels of antioxidant enzymes in patients with osteoarthritis. BMC Musculoskelet Disord. 2011;12:264.

49. Beecher BR, Martin JA, Pedersen DR, Heiner AD, Buckwalter JA. Antioxidants block cyclic loading induced chondrocyte death. Iowa Orthop J. 2007;27:1-8.

50. Yin W, Park JI, Loeser RF. Oxidative stress inhibits insulin-like growth factor-I induction of chondrocyte proteoglycan synthesis through differential regulation of phosphatidylinositol 3-kinaseAkt and MEK-ERK MAPK signaling pathways. $J$ Biol Chem. 2009;284:31972-31981.

51. Paoloni M, Di Sante L, Cacchio A, et al. Intramuscular oxygenozone therapy in the treatment of acute back pain with lumbar disc herniation: a multicenter, randomized, double-blind, clinical trial of active and simulated lumbar paravertebral injection. Spine (Phila Pa 1976). 2009;34:1337-1344.
52. Bellomo RG, Paolucci T, Giannandrea N, Pezzi L, Saggini R. Ozone therapy and aquatic rehabilitation exercises to overcome the lumbar pain caused by facet joint syndrome - case report. Int Med Case Rep J. 2020;13:171-176.

53. Smith NL, Wilson AL, Gandhi J, Vatsia S, Khan SA. Ozone therapy: an overview of pharmacodynamics, current research, and clinical utility. Med Gas Res. 2017;7:212-219.

54. Zanardi I, Borrelli E, Valacchi G, Travagli V, Bocci V. Ozone: A multifaceted molecule with unexpected therapeutic activity. Curr Med Chem. 2016;23:304-314.

55. Valdenassi L, Franzini M, Simonetti V, Ricevuti G. Oxygen-ozone therapy: paradoxical stimulation of ozone. Ozone Ther. 2016;1:24.

56. Richelmi P, Valdenassi L, Bertè F. Pharmacological principles underlying oxygen-ozone therapy. Neuroradiol J. 2001;14:17-22.

57. Di Mauro R, Cantarella G, Bernardini R, et al. The biochemical and pharmacological properties of ozone: the smell of protection in acute and chronic diseases. Int J Mol Sci. 2019;20:634.

58. Choi MC, Jo J, Park J, Kang HK, Park Y. NF-кB signaling pathways in osteoarthritic cartilage destruction. Cells. 2019;8:734.

59. Murrell GA, Jang D, Williams RJ. Nitric oxide activates metalloprotease enzymes in articular cartilage. Biochem Biophys Res Commun. 1995;206:15-21.

60. Burkhardt H, Schwingel M, Menninger H, Macartney HW, Tschesche H. Oxygen radicals as effectors of cartilage destruction. Direct degradative effect on matrix components and indirect action via activation of latent collagenase from polymorphonuclear leukocytes. Arthritis Rheum. 1986;29:379-387.

61. Vaillant JD, Fraga A, Díaz MT, et al. Ozone oxidative postconditioning ameliorates joint damage and decreases pro-inflammatory cytokine levels and oxidative stress in PG/PS-induced arthritis in rats. Eur J Pharmacol. 2013;714:318-324.

62. Karouzakis E, Neidhart M, Gay RE, Gay S. Molecular and cellular basis of rheumatoid joint destruction. Immunol Lett. 2006;106:813.

Date of submission: August 11, 2020

Date of decision: September 31, 2020

Date of acceptance: January 11, 2021

Date of web publication: June 28 ,

2021 